\title{
Treatment of intractable parotid sialocele occurred after open reduction-fixation of mandibular subcondylar fracture
}

\author{
Jungil Hwang, \\ Yong Chun You, \\ Jin Sik Burm
}

Department of Plastic Surgery, Kyung Hee University Medical Center, Kyung Hee

University School of Medicine, Seoul, Korea

\begin{abstract}
A sialocele is a subcutaneous cavity containing saliva, most often caused by facial trauma or iatrogenic complications. In subcondylar fractures, most surgeons are conscious of facial nerve injury; however, they usually pay little attention to the parotid duct injury. We report the case of a 41 -year-old man with a sialocele, approximately $5 \times 3 \mathrm{~cm}$ in size, which developed 1 week after subcondylar fracture reduction. The sialocele became progressively enlarged despite conservative management. Computed tomography showed a thin-walled cyst between the body and tail of the parotid gland. Fluid leakage outside the cyst was noted where the skin was thin. Sialography showed a cutting edge of the inferior interlobular major duct before forming the common major duct that seemed to be injured during the subcondylar fracture reduction process. We decided on prompt surgical treatment, and the sialocele was completely excised. A duct from the parotid tail, secreting salivary secretion into the cyst, was ligated. Botulinum toxin was administrated to block the salivary secretion and preventing recurrence. Treatment was successful. In addition, we found that parotid major ducts are enveloped by the deep lobe and extensive dissection during the subcondylar fracture reduction may cause parotid major duct injury.
\end{abstract}

Keywords: Parotid gland / Sialocele / Mandibular fractures / Intraoperative complications / Botulinum toxins

\section{INTRODUCTION}

The transparotid approach provides direct access to mandibular ramus and condylar fractures. In subcondylar fractures, complete exposure of the fracture site requires extended dissection to the sigmoid notch. Most surgeons are very conscious of the facial nerve injury when approaching through the parotid gland to the fracture areas. However, they usually pay little attention to the parotid duct or branch injury even though the duct injury may lead to a sialocele or sialo-cutaneous fistula. We experienced a case of intractable parotid sialocele that occurred after reduction-

Correspondence: Jin Sik Burm

Department of Plastic Surgery, Kyung Hee University Medical Center, 23 Kyungheedaero, Dongdaemun-gu, Seoul 02447, Korea

E-mail: jsburm@gmail.com

Received March 2, 2018 / Revised June 4, 2018 / Accepted June 8, 2018 fixation of a mandibular subcondylar fracture via the retromandibular transparotid approach. It was successfully treated with a combination of complete excision and botulinum toxin injection. We also discuss the surgical anatomy of the parotid duct with respect to the major tributaries and their relationship to sialocele formation.

\section{CASE REPORT}

A 41-year-old man presented for mandibular subcondylar fracture which was reconstructed with direct open reduction and internal fixation of the condyle via the retromandibular transparotid approach. Two weeks after the surgery, he revisited our outpatient office with a chief concern of swelling approximately $5 \times 3 \mathrm{~cm}$ in size under the surgical incision wound on the left retromandibu- 
lar area for the past 1 week (Fig. 1). He did not have pain; however, complained of the swelling increased during meals. Physical examination showed a soft subcutaneous cystic mass. These findings suggested a sialocele.

A $4 \mathrm{~mL}$ of aspiration was performed and serosanguinous fluid was observed. Triamcinolone $(0.2 \mathrm{~mL} \times 40 \mathrm{mg} / \mathrm{mL})$ and bleomycin $(0.2 \mathrm{~mL} \times 1 \mathrm{mg} / \mathrm{mL})$ were administered. Pressure dressing was applied. However, the 2 weeks of treatment was not effective. After 2 weeks, the sialocele size did not decrease and the skin overlying the sialocele was thinning. A $5 \mathrm{~mL}$ of aspiration was performed again and the serosanguinous fluid had become turbid. This fluid analysis showed no bacterial growth and high amylase levels $(17,250$ units/L). Triamcinolone and bleomycin were administered again, and pressure dressing was applied continuously.

We conducted computed tomography and sialogram for the further evaluation. Computed tomography revealed a well-defined thin-walled cyst $(32 \times 22 \times 21 \mathrm{~mm})$ below the earlobe and retromandibular area between the body and tail of the parotid gland (Fig. 2A). The lateral portion of the cyst was damaged and fluid leakage outside the cyst was noted where the skin was thin. Sialography of the left parotid gland showed no accumulation of contrast media in the sialocele location when the contrast media was injected through the intraoral Stensen's duct orifice. It revealed no connection between the Stensen's duct and the sialocele. A cutting edge of the inferior interlobular duct was noted (Fig. 2B). Contrast media was percutaneously injected into the si-

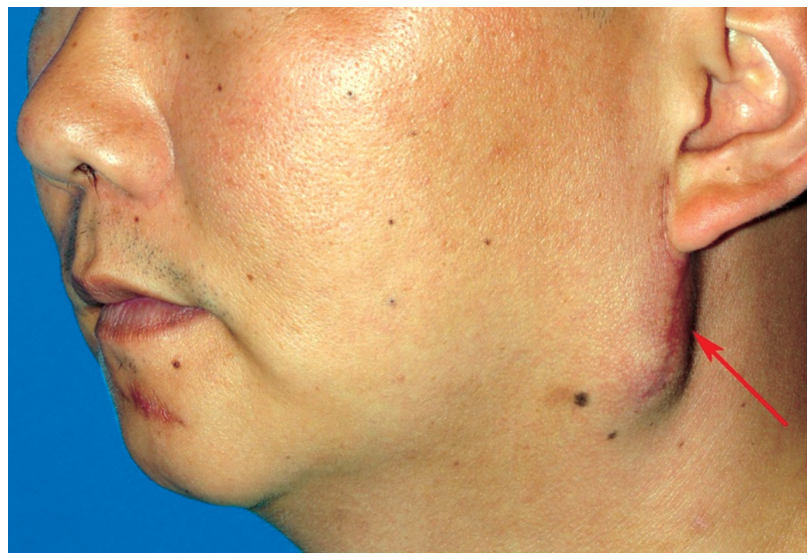

Fig. 1. Retromandibular swelling approximately $5 \times 3 \mathrm{~cm}$ in size (arrow) and fluctuation developed weeks after subcondylar fracture reduction.
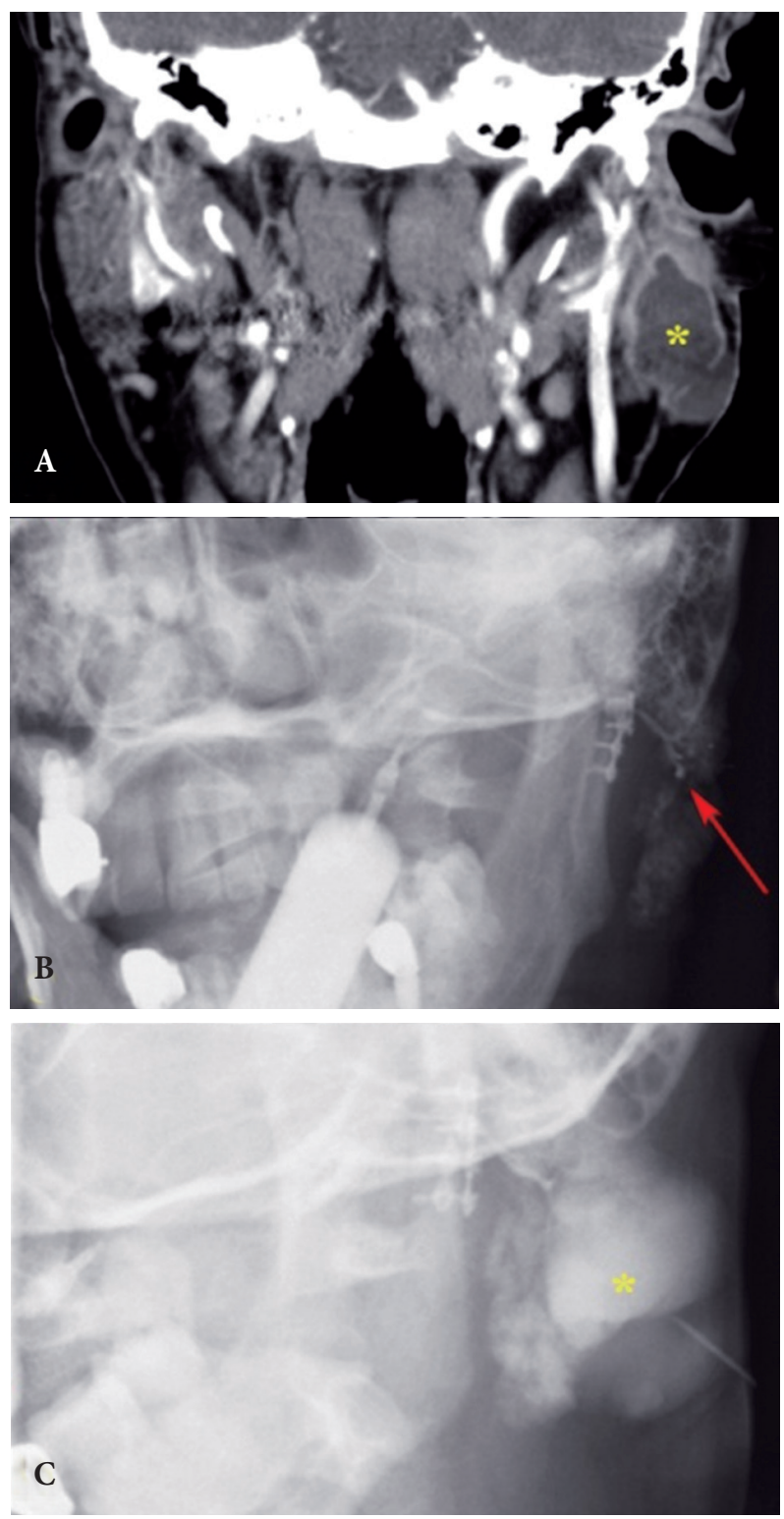

Fig. 2. Radiographic findings of the sialocele. (A) Computed tomography shows a well-defined thin-walled sialocele (asterisk) between the body and tail of the left parotid gland. (B) Sialogram of the left parotid gland through the Stensen's duct orifice showed no accumulation of contrast media in the sialocele. The arrow indicates the cutting end of inferior interlobular duct. (C) Sialogram by percutaneous contrast media injection shows the sialocele (asterisk) which was located at the tail of the parotid gland.

alocele which was located at the tail of the parotid gland where the inferolateral part of the cutting end of parotid duct was positioned (Fig. 2C). It revealed an approximately $30 \times 25 \mathrm{~mm}$ cyst located at the lateral area of the transected parotid duct lesion as well as fluid leakage outside the parotid fascia. The sialocele had 
impending sings of trans-cutaneous fistula, which prompted surgical treatment.

The patient underwent surgery through the previous incision line. The sialocele was located beneath the skin and encapsulated with thin capsule that was the part of protruded parotid fascia. Dissection was conducted to parotid fascia layer. The parotid gland was dissected along the sialocele wall that was located between the parotid body and tail area (Fig. 3A). Two openings of transected ducts were noted at the base of the inside cavity which were $1.5 \mathrm{~cm}$ apart and marked. After complete excision of the sialocele wall, we further dissected the both duct openings and ligated the both ends with 5-0 vicryl suture (Fig. 3B). Fifty IU of botulinum toxin type A was injected into the parotid gland around and distal to the sialocele to block salivary secretion and preventing recurrence (Fig. 3B). The cyst-excised space was packed with surrounded parotid glandular tissue and tightly sutured. A negative suction drain was placed and pressure dressing applied. No discharge was noted 2 days postoperatively, and the drain was removed. The patient was discharged without any symptoms. No complications or recurrence were observed at 7-month follow-up (Fig. 4). Postoperative computed tomography also showed no recurrence of the sialocele.

\section{DISCUSSION}

The parotid gland is located below and in front of each ear canal and above the inferior border of mandible. Each gland lies posterolateral to the mandibular ramus and masseter muscle and anterolateral to the mastoid process of temporal bone [1]. Richards et al. [2] reported on the major tributaries of the parotid duct, observed that the bifurcated pattern (48\%), two major duct branches form the common duct within the deep lobe, was the most common pattern, followed by the single pattern $(31 \%)$, the trifurcated pattern (7\%), multiple branch pattern (7\%) and the bifurcated pattern out of the gland (7\%). In all cases, the parotid major duct was enveloped by the deep lobe of the parotid gland, only small ductules of the superficial lobe connect with the duct. The parotid duct was always observed medial to the facial nerve branches.

Sialocele is a rare complication characterized by subcutaneous
A

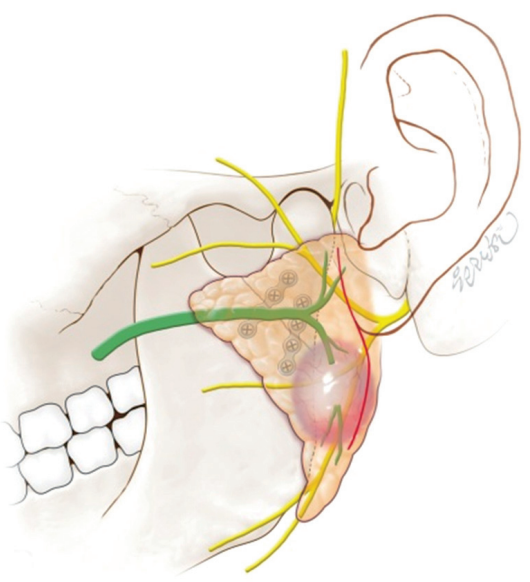

B

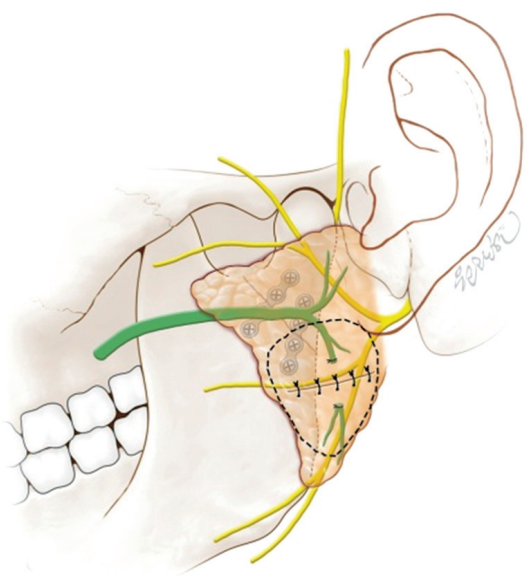

Fig. 3. Anatomical relationship and correction of a sialocele. (A) Anatomical relationship of subcondylar fracture to the parotid gland, intralobular ducts and sialocele. Severed intralobular duct in the parotid gland tail located in the path from the retromandibular incision line (red line) to the fracture site. (B) Surgical correction. Complete excision of the sialocele and proximal duct ligation state was performed, followed by botulinum toxin injection (dotted circle).

cavity containing parotid saliva. It is caused by trauma, neoplastic process, or surgery to parotid gland lesion [3]. Ductule injury, which is located at the superficial lobe, may regress spontaneously or be treated easily using nonsurgical treatments such as repeated aspiration, compressive dressing, medication of acetylcholine release blocker, and/or botulinum toxin injection [2-4]. However, major duct injury at the deep lobe may cause intractable sialocele. Continuous salivary fluid secretion to the sialocele and the stagnant fluid may break out of the cavity through cutaneous skin developing into a transcutaneous fistula. These major duct injury sialocele should be treatment with intraoral catheter drainage, 


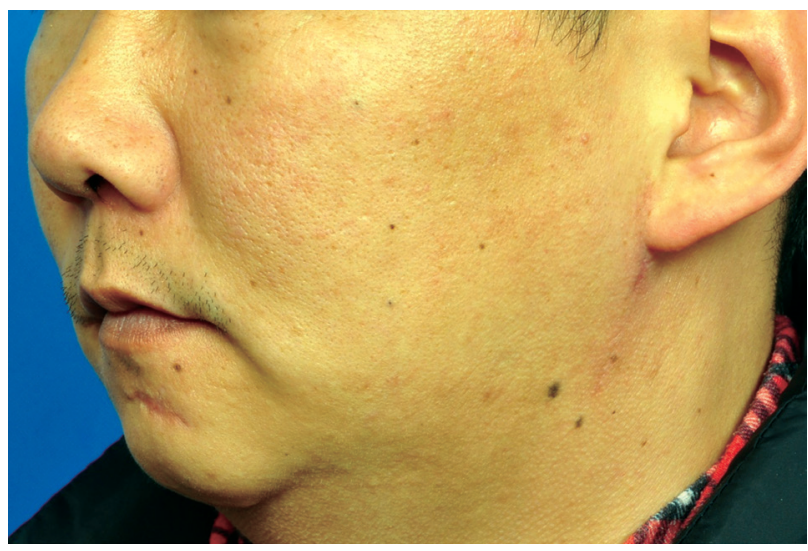

Fig. 4. Clinical photograph at 7-month follow-up.

surgical excision of the cyst, and/or parotidectomy as well as conservative treatment modality mentioned above [3-5].

For the subcondylar fractures, preauricular approach is too high to access below the sigmoid notch regions [6] and submandibular approach is too low to access the subcondylar regions $[6,7]$ and requires extensive stretching the facial nerve branches and may cause transient facial nerve weakness [8] when exposing the lesions. The retromandibular incision is closer to the subcondylar fracture sites [7,9]; however, the retromandibular incision only may achieve a limited exposure [10]. Therefore, this case patient who had subcondylar fracture extending to the condylar neck region was treated with transparotid retromandibular incision extending to the preauricular earlobe lesion. The extended retromandibular approach provided better visualization and alignment for the fracture lesions with good cosmetic result. After the skin incision for the transparotid retromandibular approach, the skin flap is raised above the parotid fascia layer [5,11]. A parotid fascia incision is placed and blunt dissection is done in the parotid gland substance for finding the facial nerve branches and moving them away. During the procedures, parotid duct injury, salivary fluid accumulation and inappropriate position of drain tube may cause the sialocele.

Our patient had a subcondylar fracture extending to the sigmoid notch region. The subcondylar fracture was located between the buccal and zygomatic nerve. The inferior branch of the parotid duct ran along the posterior portion of the mandible. Extensive dissection of buccal and zygomatic nerve and periosteal elevation between the nerves were required for visualization of the subcondylar fracture site including its sigmoid notch region. During these dissection process, the inferior branch of parotid duct in the deep lobe might have been exposed. We thought the exposed duct might have been damaged or transected as the parotid gland parenchyma was dissected. Another reason for parotid duct injury might be for the intensive traction force applied for the drilling process and plate fixation, especially for the sigmoid notch or the anterior portion of the fracture site. The sialogram revealed the transected inferior branch of the parotid duct which was the area where dissection and traction force were applied. Previous report described that the parotid fascia could be damaged during the subcondylar fracture surgery, and the inadequate closure of the parotid fascia might have an effect on the formation of sialocele [5].

It was reported that patients with sialoceles or sialo-cutaneous fistulas were treated using botulinum toxin injections [12,13]. Hypersialorrhea treatment commonly requires approximately 20 to $30 \mathrm{IU}$ of botulinum toxin to reduce salivary flow. Case studies of patients with sialoceles or sialo-cutaneous fistulas reported using local injections of 50 to $100 \mathrm{IU}$ of botulinum toxin. Botulinum toxin only is effective for some types of sialoceles. Arnaud et al. [12] reported treating a sialocele using botulinum toxin without surgical intervention although treatment involved toxin administration every 3 months for 9 months. Hong et al. [13] reported treating an iatrogenic sialo-cutaneous fistula using botulinum toxin only. However, the patient had intact parotid fascia during a previous cancer excision surgery, suggesting that the parotid injury was in the superficial lobe area and did not involve major duct injury. Although parotid minor ductule injury may be treated conservatively, our case involved parotid major duct injury, turbid aspiration fluid, and decrease in skin thickness, which required prompt treatment. Thus, we planned surgical intervention accompanied with botulinum toxin injection. A duct from the parotid tail secreting saliva into the cyst was ligated to block salivary influx. Botulinum toxin (50 IU) was injected around the sialocele, whole the parotid tail area, and the area adjacent to the transected parotid duct. This combination was very successful. Intraoperative injection of botulinum toxin may guarantee blocking salivary secretion and preventing recurrence of sialocele. 


\section{CONFLICT OF INTEREST}

No potential conflict of interest relevant to this article was reported.

\section{PATIENT CONSENT}

The patients provided written informed consent for the publication and the use of their images.

\section{REFERENCES}

1. Fehrenbach MJ, Herring SW. Illustrated anatomy of the head and neck. St. Louis: Elsevier; 2012.

2. Richards AT, Digges N, Norton NS, Quinn TH, Say P, Galer C, et al. Surgical anatomy of the parotid duct with emphasis on the major tributaries forming the duct and the relationship of the facial nerve to the duct. Clin Anat 2004;17:463-7.

3. Araujo MR, Centurion BS, Albuquerque DF, Marchesano LH, Damante JH. Management of a parotid sialocele in a young patient: case report and literature review. J Appl Oral Sci 2010;18:432-6.

4. Parekh D, Glezerson G, Stewart M, Esser J, Lawson HH. Post-traumatic parotid fistulae and sialoceles: a prospective study of conservative management in 51 cases. Ann Surg 1989;209:105-11.
5. Balaji SM. Parotid fistula from transparotid approach for mandibular subcondylar fracture reduction. Ann Maxillofac Surg 2013;3:182-4.

6. Ellis E 3rd, Dean J. Rigid fixation of mandibular condyle fractures. Oral Surg Oral Med Oral Pathol 1993;76:6-15.

7. Ghezta NK, Bhardwaj Y, Rani P, Ram R. Efficacy of retromandibular transparotid approach for the management of extracapsular subcondylar mandibular fractures using 2-mm titanium miniplates: a prospective clinical study. J Oral Maxillofac Surg 2016;74:1613-21.

8. Gerbino G, Boffano P, Tosco P, Berrone S. Long-term clinical and radiological outcomes for the surgical treatment of mandibular condylar fractures. J Oral Maxillofac Surg 2009;67:1009-14.

9. Yang L, Patil PM. The retromandibular transparotid approach to mandibular subcondylar fractures. Int J Oral Maxillofac Surg 2012;41: 494-9.

10. Vesnaver A, Gorjanc M, Eberlinc A, Dovsak DA, Kansky AA. The periauricular transparotid approach for open reduction and internal fixation of condylar fractures. JCraniomaxillofac Surg 2005;33:169-79.

11. Croce A, Moretti A, Vitullo F, Castriotta A, Rosa de M, Citraro L. Transparotid approach for mandibular condylar neck and subcondylar fractures. Acta Otorhinolaryngol Ital 2010;30:303-9.

12. Arnaud S, Batifol D, Goudot P, Yachouh J. Nonsurgical management of traumatic injuries of the parotid gland and duct using type a botulinum toxin. Plast Reconstr Surg 2006;117:2426-30.

13. Hong SE, Kwon JW, Kang SR, Park BY. The effect of botulinum toxin on an iatrogenic sialo-cutaneous fistula. Arch Craniofac Surg 2016;17:237-9. 